\title{
Implantable Cardioverter-Defibrillator Placement
}

National Cancer Institute

\section{Source}

National Cancer Institute. Implantable Cardioverter-Defibrillator Placement. NCI

Thesaurus. Code C80435.

A surgical procedure in which a small, battery-powered device is placed in the chest wall to detect arrhythmias and correct them by delivering a jolt of electricity. 